\title{
Safety of abatacept compared with other biologic and conventional synthetic disease-modifying antirheumatic drugs in patients with rheumatoid arthritis: data from an observational study
}

\author{
Gulsen Ozen ${ }^{1}$, Sofia Pedro², Rebecca Schumacher ${ }^{2}$, Teresa A. Simon ${ }^{3}$ and Kaleb Michaud ${ }^{1,2^{*}}$ (D)
}

\begin{abstract}
Background: To assess the risks of malignancies, infections and autoimmune diseases in patients with rheumatoid arthritis (RA) treated with abatacept compared with other biologic (b) disease-modifying antirheumatic drugs (DMARDs) or conventional synthetic (cs)DMARDs, in a US-wide observational RA cohort

Methods: Data were reviewed from patients ( $\geq 18$ years) with RA who were registered with FORWARD, the National Databank for Rheumatic Diseases, and who initiated abatacept, other bDMARDs or csDMARDs between 2005 and 2015. Patients who switched treatment during the study could be allocated to more than one group. The incidence rates (IRs) by treatment were calculated for malignancies, hospitalized infections and autoimmune diseases identified by six monthly questionnaires and medical records. The hazard ratios (HRs) (95\% confidence intervals [Cls]) for all outcomes with abatacept compared with other bDMARDs or csDMARDs were determined using marginal structural models adjusted for clinical confounders.
\end{abstract}

Results: In the study sample, 1496 initiated abatacept, 3490 initiated another bDMARD and 1520 initiated a cSDMARD. The risk of malignancies with abatacept was not statistically significant versus other bDMARDs (HR [95\% CI)] $1.89[0.93$, 3.84]) or versus CsDMARDs (HR [95\% CI] $0.93[0.20,4.27])$. Patients receiving abatacept versus other bDMARDs were at a lower risk of hospitalized infections ( $\mathrm{HR}[95 \% \mathrm{CI} 0.37[0.18,0.75]$ ); the risk versus csDMARDs was lower with wide Cls $(\mathrm{HR}[95 \% \mathrm{Cl}] 0.31[0.09,1.05])$. The relative risks for psoriasis were similar between treatment groups (HR [95\% Cl] 1.46 $[0.76,2.81]$ and $\mathrm{HR}[95 \% \mathrm{CI}] 2.05[0.59,7.16]$ for abatacept versus other bDMARDs and versus csDMARDS, respectively). The IR $(95 \% \mathrm{Cl})$ of severe infusion/injection reactions was lower with abatacept compared with other bDMARDs (1.57 $[1.11,2.17]$ vs $2.31[1.87,2.82]$ per 100 patient-years, respectively).

Conclusions: In this analysis, abatacept was well tolerated and did not result in an overall increased risk of malignancies, infections or autoimmune diseases compared with other bDMARDs or csDMARDs.

Keywords: Abatacept, Autoimmune disease, Infection, Malignancy, Observational, Rheumatoid arthritis, Safety

\footnotetext{
* Correspondence: kmichaud@unmc.edu

'University of Nebraska Medical Center, Omaha, NE, USA

${ }^{2}$ FORWARD, The National Databank for Rheumatic Diseases, Wichita, KS, USA

Full list of author information is available at the end of the article
}

(c) The Author(s). 2019 Open Access This article is distributed under the terms of the Creative Commons Attribution 4.0 International License (http://creativecommons.org/licenses/by/4.0/), which permits unrestricted use, distribution, and reproduction in any medium, provided you give appropriate credit to the original author(s) and the source, provide a link to the Creative Commons license, and indicate if changes were made. The Creative Commons Public Domain Dedication waiver (http://creativecommons.org/publicdomain/zero/1.0/) applies to the data made available in this article, unless otherwise stated. 


\section{Background}

The introduction of biologic (b) disease-modifying antirheumatic drugs (DMARDs) into clinical practice has been a major advancement for patients with rheumatoid arthritis (RA) in whom treatment with conventional synthetic (cs) DMARDs has failed, and has contributed to the improved outcomes in RA reported over the previous two decades $[1,2]$. The short-term safety of bDMARDs has been documented in clinical trials; however, the long-term safety of bDMARDs is of clinical interest in the population of patients with RA [3]. In particular, the risk of malignancies and hospitalized infections in patients with RA is higher than in the general population $[4,5]$, and there is a need to differentiate between the long-term effects of RA and those associated with bDMARD treatment. Additionally, most safety data in the literature relate to tumour necrosis factor- $\alpha$ inhibitors (TNFis), and more studies are needed relating to the safety of other bDMARDs and targeted synthetic DMARDs [3].

Abatacept is a fully human, selective T cell co-stimulation modulator that was approved in the USA for the treatment of RA in 2005. The efficacy of abatacept in RA in both biologic-naïve patients and in those with previous DDMARD failure has been demonstrated in several randomized controlled trials (RCTs) [6-15]. The safety findings across these studies were consistent between trials, and integrated analyses reflecting the long-term safety of intravenous (IV) and subcutaneous (SC) abatacept reported similar and stable incidence rates (IRs) of serious infections (SIs), malignancies, autoimmune events and infusion reactions, with no new safety signals over time [6-12, 14-17]. However, the relevance of these findings to the longer-term use of abatacept in clinical practice may be limited by the stringent patient inclusion criteria, short follow-up periods and limited power restraints for the detection of adverse events (AEs) in RCTs. Data from observational studies can supplement RCT safety data to broaden the understanding of the risks associated with abatacept treatment over time in a typically heterogeneous, clinical RA population. To date, observational findings for the safety of abatacept are mostly derived from biologic- or abatacept-specific registries of administrative or pharmacy data. Analyses of these data have generated conflicting results, possibly due to considerable variations in factors such as study population, comparators, outcome definitions, confounders and AEs [18-25]. Comparative observational data on the IRs of malignancies with abatacept are also inconsistent [26, 27]; however, when compared with other bDMARDs, abatacept has been associated with a higher relative risk of nonmelanoma skin cancers (NMSCs) [23, 28]. Comparative data for the risk of SIs with abatacept versus other bDMARDs are similarly conflicting [19, 20, 22, 25, 29], and there are no data directly comparing the risk of SIs with abatacept versus csDMARDs $[19,25]$.
The abatacept global post-marketing epidemiology programme was designed to evaluate infection and malignancy risks associated with abatacept (initially intended as a first-line DMARD) compared with those of csDMARDs for the treatment of RA. The programme spanned more than 10 years and consists of observational studies based on biologic disease registries and healthcare claims databases, such as FORWARD (the National Databank for Rheumatic Diseases) - a US-wide registry that enrolls patients with rheumatic diseases in the community [29]. Information from patients is obtained from questionnaires every 6 months and is validated when required using medical records.

The aim of this analysis was to assess the risks of malignancies, infections, autoimmune diseases and mortality in patients with RA treated with abatacept compared with other bDMARDs or csDMARDs in an observational cohort of patients enrolled in the US FORWARD registry.

\section{Methods}

This analysis utilized data from FORWARD, an ongoing, longitudinal, prospective, observational study in the USA, which has been described in detail previously [29]. Patient-recorded details collected by bi-annual questionnaires were analysed and included all medications taken in the previous 6 months (including doses, months taken, start and stop dates, reasons for discontinuation and side effects). Other information collected included patient demographics, socioeconomic data, co-morbidities, medical events, health-related quality of life, health symptoms and RA-specific outcome measures. The last questionnaire used for this analysis was administrated between January and June 2016 and reflected the events of the preceding 6-month period (August to December 2015) [29, 30]. The analysis population comprised all those who completed at least one full questionnaire and initiated a new course (incident users) of either abatacept, other bDMARDs (adalimumab, anakinra, certolizumab, etanercept, golimumab, infliximab, rituximab and tocilizumab) or csDMARDs (methotrexate, hydroxychloroquine, leflunomide and sulfasalazine) during the study period. The design of the analysis and inclusion of comparison arms helped mitigate complications with data capture. Each initiator of abatacept was matched with initiators of other RA treatments by date of cohort entry in a maximum of a 1:3 ratio. Patients in the abatacept group were defined as those who initiated abatacept or switched to abatacept after starting another bDMARD or a csDMARD. Patients in the comparator treatment groups were defined as those with no history of abatacept treatment. Patients in the comparator groups who switched to abatacept following treatment with another bDMARD or a csDMARD were included in the abatacept group and contributed to both the comparator (up to point of switch) and abatacept (following switch) data sets. Baseline was defined as the 
treatment start date; patients who switched treatment during the study could be allocated to more than one group. The database was locked on 4 June 2016.

\section{Patients}

Patients enrolled in FORWARD and eligible for inclusion in this analysis were aged $\geq 18$ years, had a confirmed diagnosis of RA, and initiated abatacept, another bDMARD or csDMARD between 1 July 2005 and 31 December 2015 in the USA. For each endpoint, except hospitalized infections, patients with the endpoint of interest at baseline were excluded from the analysis. For the analysis of malignancies, patients with a prior history of cancer at baseline were excluded. All patients provided their written informed consent for participation in the analysis.

\section{Analysis outcomes}

The primary outcomes were malignancies (overall malignancies [including NMSC], lung cancer, lymphoma, breast cancer and NMSC), infections (hospitalized infections, pneumonia, opportunistic infections and tuberculosis) and autoimmune diseases (lupus, multiple sclerosis and psoriasis). Malignancies, infections and autoimmune diseases were identified from study questionnaires and were validated by patient and/or physician interview and medical record review, using the International Classification of Diseases, Ninth Revision, Clinical Modification diagnosis codes and hospitalization codes (see Additional file 1: Tables S1, Additional file 2: Tables S2, Additional file 3: Tables S3). Secondary outcomes included hospitalizations for any reason, any or serious infusion and/or injection reaction and death (identified and validated using the National Center for Health Statistics National Death Index). Reactions to infusions and injections were patient-reported only and were classified as 'severe' if they caused severe redness and/ or pain, changes in blood pressure, difficulty breathing, feeling ill, chills, feeling faint or any severe symptoms that required medical care.

\section{Follow-up}

Study follow-up started from initiation of abatacept, other bDMARDs or csDMARDs and continued until the first development of any study outcome, treatment discontinuation, death, loss to follow-up or end of study period, whichever came first. Hospitalized infections were attributed to the corresponding treatment group when the treatment was ongoing or discontinued $\leq 3$ months previously. This risk window was extended to $\leq 12$ months for rituximab due to its long-term effects on $B$ cells. For the assessment of hospitalized infections, this risk window after treatment discontinuation was included in the follow-up period for patients who discontinued therapy for any other reason.

\section{Statistical analysis}

Overall IRs for each outcome with 95\% confidence intervals (CIs) were calculated by dividing the number of events for each endpoint by the total patient-time at risk. Only the occurrence of the first event of interest was considered, and the corresponding rates per 100 patient-years were determined. The risks of malignancies, infections and selected autoimmune disease infections were quantified in patients receiving abatacept versus other bDMARDs and abatacept versus csDMARDs using marginal structural models (MSMs). Results were presented as hazard ratios (HRs) with 95\% CIs.

MSMs allow proper adjustment of time-varying confounders that are also affected by prior treatment [31]. For this analysis, the inverse probability of treatment weights (IPTWs) were derived from each patient's treatment history and time-varying confounders. These IPTWs were then used in a logistic regression model to control for the time-dependent confounding in the outcome-treatment association, allowing less biased estimates to be obtained [32]. The IPTWs created a pseudo-population in which patients receiving treatment and those not receiving treatment were balanced over the time-varying confounders, but the relationship between treatment and outcome was not altered. The HR was obtained by using a weighted pooled logistic regression (which is equivalent to a Cox model when the hazard of treatment is small) for the probability of receiving abatacept at a given time using the following time-varying covariates measured at baseline and point of measurement: age, sex, employment status (yes/no), annual income ( $\leq 45 \mathrm{~K} \mathrm{USD},>45 \mathrm{~K}$ USD), education level ( $\leq 12$ years, $13-15$ years, $\geq 16$ years), smoking status (never, current and past), disease duration $(\leq 3$ years, 4-10 years, $\geq 11$ years), Health Assessment Questionnaire-Disability Index (HAQ-DI), pain and patient global scores by visual analogue scale (0-10), body mass index, Rheumatic Diseases Comorbidity Index score, any chronic lung disease (yes/no), diabetes (yes/no), number of prior bDMARDs $(0,1,2, \geq 3)$, glucocorticoid (GC) use (yes/no, duration, daily dose $[<7.5 \mathrm{mg} /$ day, $7.5-<15$ $\mathrm{mg} /$ day, $\geq 15 \mathrm{mg} /$ day]), year of study entry (2005-2007, 2008-2010, 2011-2013, 2014-2015) and follow-up time using a three-knot spline. Considering the effects of increasing age, co-morbidities, disease duration, and severity measures on the outcomes, time-varying age, disease duration, HAQ-DI, pain and patient global scores, Rheumatic Disease Comorbidity Index (RDCI) and GC treatment duration were also included in the model. The dataset was discretized into one observation per month, and the hazard of treatment in any month was considered small [33]. Due to the low number of events for subtypes of malignancies, infections and autoimmune diseases, MSMs were created only for overall malignancies, NMSC and hospitalized infections. 
In order to prevent bias from removing observations due to missing data, all missing covariates of the completed questionnaires were replaced by using multiple imputation by chained equations to create multiple imputed datasets for analyses. Since the odds ratios from MSMs are equivalent to the HRs that would be obtained from the Cox models, the results were presented as HR (95\% CI). An intention-to-treat analysis was performed for all outcomes except hospitalized infections where an on-treatment plus 90 days was preferred. The weights were corrected for loss of follow-up and, for infection outcomes, induced selection bias due to artificial censoring (i.e. treatment noncompliance). All $p$ values were two-sided and were conducted at a significance level of 0.05. All statistical analyses were performed using Stata/ MP version 14.2 (StataCorp, College Station, TX, USA).

\section{Results}

The analysis included 1496 patients who initiated abatacept with 4896 patient-years of total follow-up and 2502 patientyears of abatacept exposure; 3490 patients who initiated another bDMARD with 11,777 patient-years of total followup (9658 patient-years of drug exposure); and 1520 patients who initiated a csDMARD with 4816 patient-years of total follow-up (4184 patient-years of drug exposure). Median follow-up was 2.5 years per patient (interquartile range [IQR] 1.0-4.5 years) for abatacept and bDMARDs and 2.0 years per patient (IQR 1.0-4.0 years) for csDMARDs.

Patient baseline characteristics by treatment group are presented in Table 1. At baseline, patients initiating abatacept versus other bDMARDs or csDMARDs tended to have higher HAQ-DI, pain and patient global scores, and greater proportions of patients had prior use of csDMARDs and concurrent use of a GC. Prior use of a bDMARD was more frequent in abatacept versus other bDMARD initiators ( $\geq 2$ bDMARDs, $50.2 \%$ vs $27.8 \%$, respectively), and most patients in both groups were on a concomitant csDMARD (73\% and 76\%, respectively).

\section{Outcomes}

In the fully adjusted MSMs, there were no differences in the risks of malignancies with abatacept relative to other bDMARDs or to csDMARDs (Fig. 1). The relative risks of breast cancer, lung cancer and lymphoma could not be determined because none of these events was observed in any treatment group. Overall, abatacept treatment was associated with a lower risk of all hospitalized infections compared with other bDMARDs (adjusted HR [95\% CI] 0.37 $[0.18,0.75]$ ), and with a lower risk (wide CIs) compared with csDMARDs $(0.31[0.09,1.05])$. When analysis was limited to line of therapy (second-line, third-line or greater), the risk difference in hospitalized infections between abatacept and other bDMARDs and csDMARDs decreased (Table 2). The number of overall autoimmune events was low, and most models used to analyse the relative risks of these secondary outcomes did not converge. There was a numerical increase in the risk of psoriasis with abatacept compared with other bDMARDs and with csDMARDs. The relative risks of hospitalized infections, malignancies and NMSCs by abatacept treatment line are presented in Table 2.

For the secondary outcomes (except psoriasis), the results were presented as crude IRs due to the low number of events and inability to achieve convergence by the MSMs.

The IR of overall malignancy was higher in the abatacept group than in the other bDMARD group, and was lower than in the csDMARD group (Table 3). The most frequently observed malignancy was NMSC in all treatment groups.

The IRs of infections were similar across treatment groups, with lower rates of hospitalized infections or pneumonia with abatacept versus other bDMARDs or csDMARDs (Table 3). No cases of tuberculosis were observed in any treatment group. The IRs of autoimmune diseases were mostly similar across treatments; however, a higher incidence of psoriasis was reported in the abatacept versus other treatment groups (Table 3). The highest frequency of hospitalizations was observed in the csDMARD treatment group, and death rates were comparable across treatments (Table 3).

The IRs for any reaction to treatment infusion or injection were lower with abatacept than with other bDMARDs; severe administration reactions were less common with SC than with IV abatacept (Table 4).

\section{Discussion}

In this US-wide observational cohort study of patients with RA, abatacept was associated with low IRs of malignancies, infections, autoimmune diseases, infusion/injection reactions and mortality, with no new safety signals. The incidence of infusion/injection-site reactions was lower with abatacept than with other bDMARDs. The risks of overall malignancies, infections and autoimmune diseases were comparable across treatment groups; however, the risk of hospitalized infection was lower with abatacept than with other bDMARDs.

Our study showed a low IR of new malignancies with abatacept. To date, only two observational studies (Sweden national cohort and CORRONA registry) have examined the comparative risk of malignancy associated with abatacept; they reported an increased risk of NMSC with abatacept compared with csDMARDs (HR [95\% CI] 2.15 [1.31, 3.52]) [23] and methotrexate $(15.3[2.05,114.0])$ [28], whereas the comparative risks of haematological and solid malignancies were similar [23, 28]. In contrast to our analysis, both studies included patients with a prior history of malignancy, which was reflected in the higher rates of malignancy observed. The power restraints and inadequate follow-up duration of RCTs for the detection of 
Table 1 Baseline patient characteristics by treatment

\begin{tabular}{|c|c|c|c|}
\hline Variables & $\begin{array}{l}\text { Abatacept } \\
n=1496\end{array}$ & $\begin{array}{l}\text { Other bDMARDs } \\
n=3490\end{array}$ & $\begin{array}{l}\text { csDMARDs } \\
n=1520\end{array}$ \\
\hline Age, years, mean (SD) & $61.5(12.8)$ & $60.9(12.9)$ & $63.3(12.9)$ \\
\hline Female & 85.5 & 83.6 & 80.9 \\
\hline Education, years, mean (SD) & $13.8(2.3)$ & $13.9(2.3)$ & $13.6(2.4)$ \\
\hline White & 94.1 & 93.5 & 93.0 \\
\hline Disease duration, years, mean (SD) & $16.6(12.2)$ & $16.6(12.1)$ & $15.3(13.8)$ \\
\hline Rheumatic Disease Comorbidity Index score (0-9), mean (SD) & $2.1(1.7)$ & $2.0(1.6)$ & $2.0(1.6)$ \\
\hline Body mass index, $\mathrm{kg} / \mathrm{m}^{2}$, mean (SD) & $29.0(7.3)$ & $28.8(7.1)$ & $29.1(7.3)$ \\
\hline History of smoking & 42.9 & 45.2 & 48.2 \\
\hline Hypertension & 38.5 & 38.1 & 39.0 \\
\hline Diabetes & 12.2 & 11.9 & 13.7 \\
\hline History of cancer & 26.5 & 25.7 & 28.1 \\
\hline HAQ-DI score (0-3), mean (SD) & $1.3(0.7)$ & $1.2(0.7)$ & $1.1(0.7)$ \\
\hline Pain score (0-10), mean (SD) & $5.6(2.7)$ & $4.9(2.8)$ & $4.5(2.8)$ \\
\hline Patient global score (0-10), mean (SD) & $4.9(2.5)$ & $4.4(2.5)$ & $4.2(2.5)$ \\
\hline Number of prior csDMARDs, mean (SD) & $2.9(1.9)$ & $2.7(1.8)$ & $2.2(1.5)$ \\
\hline Number of prior bDMARDs, mean (SD) & $1.7(1.2)$ & $1.0(1.1)$ & $0.2(0.6)$ \\
\hline 0 & 15.2 & 41.9 & 89.3 \\
\hline 1 & 34.6 & 30.3 & 6.9 \\
\hline $2-3$ & 44.3 & 24.5 & 3.4 \\
\hline$\geq 4$ & 5.9 & 3.3 & 0.5 \\
\hline Concurrent methotrexate & 51.7 & 55.0 & 45.7 \\
\hline Concurrent other non-MTX csDMARDs & 21.0 & 21.0 & 37.0 \\
\hline Concurrent glucocorticoid $^{\dagger}$ & 43.0 & 34.0 & 31.0 \\
\hline$<7.5$ mg/day & 63.7 & 64.9 & 65.7 \\
\hline $7.5-<15$ mg/day & 25.6 & 25.1 & 22.2 \\
\hline$\geq 15 \mathrm{mg} /$ day & 10.8 & 10.1 & 12.1 \\
\hline Concurrent NSAID & 41.3 & 42.8 & 44.5 \\
\hline
\end{tabular}

The values are presented as \% unless indicated otherwise. Baseline is treatment start date; patients who switched treatment during the study could be allocated to more than one group

${ }^{\dagger}$ As prednisone dose equivalents

bDMARD biologic disease-modifying antirheumatic drug, CSDMARD conventional synthetic disease-modifying antirheumatic drug, HAQ-DI Health Assessment Questionnaire-Disability Index, MTX methotrexate, NSAID nonsteroidal anti-inflammatory drug, SD standard deviation

malignancies and the scarcity of observational data suggest further research is warranted to improve understanding of the risk of malignancy associated with abatacept, particularly in comparison with other bDMARDs.

The incidence of hospitalized infections with abatacept in this analysis was lower than that reported in other observational studies, possibly due to differences in the characteristics of the study populations, such as patients' sex and co-morbidities $[20,25]$, or in the definitions used for infections [22].

Following adjustment for clinical factors influencing infection risk, we found that the overall risk of hospitalized infections with abatacept was lower than that of other bDMARDs and csDMARDs. When limited by line of therapy, the risk difference in hospitalized infections between abatacept and other bDMARD groups decreased, possibly due to infections from prior drugs precluding further use of bDMARDs. Although the comparative data currently available are limited and inconsistent, our findings are consistent with an overall trend toward a lower risk of hospitalized infections or SIs with abatacept compared with other bDMARDs $[19,22,25,34]$. Observational findings from administrative datasets have shown that compared with other bDMARDs, abatacept was associated with a lower risk of SIs $(19,25)$. Conversely, other observational studies found that SI risk with abatacept was comparable with that of rituximab [22] and etanercept [34]. Although the risk of SIs with abatacept compared with other bDMARDs observed in our analysis was lower, the risk estimate was smaller. This difference could be due 


\section{A) Abatacept vs other bDMARDs}

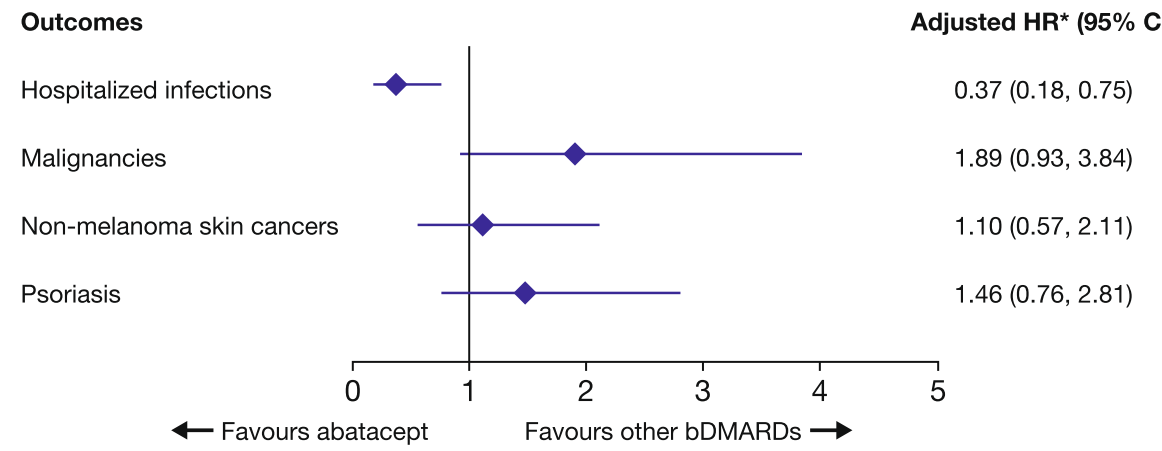

\section{B) Abatacept vs csDMARDs}

Outcomes

Hospitalized infections

Malignancies

Non-melanoma skin cancers

Psoriasis
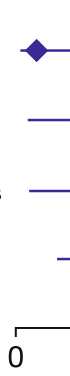

- Favours abatacep

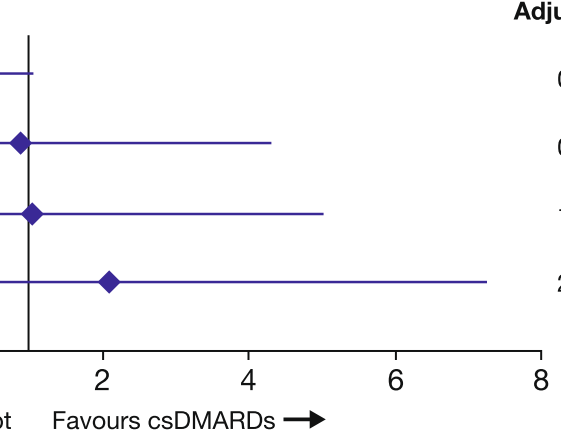

Adjusted $\mathrm{HR}^{\star}(95 \% \mathrm{Cl})$

$0.31(0.09,1.05)$

$0.93(0.20,4.27)$

$1.05(0.22,4.98)$

$2.05(0.59,7.16)$

Fig. 1 Association of treatment with hospitalized infections, malignancies and psoriasis in patients with RA. a Abatacept vs other bDMARDs. b Abatacept vs other csDMARDs. *Using inverse probability of treatment weights with further adjustment for time-varying age, disease duration, HAQ-DI, pain and patient global scores, RDCl, and GC treatment duration. bDMARD = biologic disease-modifying antirheumatic drug; $\mathrm{Cl}=$ confidence interval; csDMARD = conventional synthetic disease-modifying antirheumatic drug; GC = glucocorticoid; HAQ-DI=Health Assessment Questionnaire-Disability Index; HR = hazard ratio; RA = rheumatoid arthritis; RCDI = Rheumatic Disease Comorbidity Index

to variables such as the mean age of the study population, treatment episodes (incident/prevalent use), treatment line, comparator groups, covariates included and methods used to address channelling bias. The hospitalized infection risk with abatacept treatment compared with csDMARDs in the present study is consistent with an epidemiologic assessment of data from seven clinical trials that showed the IRs of SIs with abatacept were comparable with those in patients with RA treated with csDMARDs [35]. However, we observed a lower hospitalized infection risk with abatacept treatment compared with csDMARDs despite being not significant. At baseline, csDMARD initiators were slightly older, had higher smoking frequencies and had a slightly higher dose of glucocorticoid use; these are potentially associated with infection risk. Although we used an appropriate methodology, MSM, to address the channelling bias, as an observational study there may be residual channelling due to unmeasured confounders.

In this analysis, the IRs of most autoimmune diseases were similar across treatment groups. Psoriasis was the most frequently occurring autoimmune disease in all treatment groups; however, the IRs were within the ranges reported elsewhere [13, 17]. Patients with a pre-existing autoimmune disease are known to be at an increased risk of developing another [36-38]. Psoriasis, a T cell-mediated autoimmune disease, is known to coexist with RA more frequently than with osteoarthritis [38]. As expected, we did not observe an altered risk of psoriasis with abatacept treatment compared with other bDMARDs and csDMARDs.

We observed low IRs of infusion/injection reactions with abatacept treatment. In this analysis, use of IV abatacept was associated with a slightly higher IR of severe reactions than the $\mathrm{SC}$ formulation, possibly due to the chronological availability of the two formulations, leading to the inclusion of fewer patients treated with SC abatacept and correspondingly shorter follow-up periods than for those treated with the IV formulation. A phase IIIb noninferiority study to compare the efficacy and safety of SC versus IV abatacept reported similar incidences of infusion and injection reactions $(2.2 \%$ vs $2.7 \%$, respectively) [39]. In this analysis, lower IRs of infusion/ 
Table 2 Risk of hospitalized infections and malignancies associated with abatacept in RA by line of treatment

\begin{tabular}{|c|c|c|c|c|c|c|}
\hline \multirow[t]{3}{*}{ Outcomes } & \multicolumn{6}{|c|}{ Using inverse probability of treatment weights } \\
\hline & \multicolumn{3}{|c|}{ Abatacept vs other bDMARDs } & \multicolumn{3}{|c|}{ Abatacept vs csDMARDs } \\
\hline & $\begin{array}{l}\text { No. of cases/no. } \\
\text { of patients* }\end{array}$ & $\begin{array}{l}\text { Unadjusted HR } \\
(95 \% \mathrm{Cl})\end{array}$ & $\begin{array}{l}\text { Adjusted } \mathrm{HR}^{\dagger} \\
(95 \% \mathrm{Cl})\end{array}$ & $\begin{array}{l}\text { No. of cases/no. } \\
\text { of patients* }\end{array}$ & $\begin{array}{l}\text { Unadjusted } \\
\text { HR (95\% Cl) }\end{array}$ & $\begin{array}{l}\text { Adjusted } \mathrm{HR}^{+} \\
(95 \% \mathrm{Cl})\end{array}$ \\
\hline \multicolumn{7}{|l|}{ Hospitalized infections } \\
\hline Overall & $37 / 1099$ vs $25 / 3138$ & $0.39(0.17,0.87)$ & $0.37(0.18,0.75)$ & $37 / 1099$ vs $20 / 1103$ & $0.52(0.20,1.39)$ & $0.31(0.09,1.05)$ \\
\hline First-line & $1 / 171$ vs $13 / 1191$ & NR & NR & $1 / 171$ vs $15 / 304$ & NR & NR \\
\hline Second-line & $15 / 409$ vs $7 / 1132$ & $0.49(0.23,1.03)$ & $0.42(0.18,0.97)$ & $15 / 409$ vs $4 / 119$ & $0.99(0.26,3.76)$ & NR \\
\hline Third- or greater line & $21 / 659$ vs $5 / 1192$ & $0.76(0.42,1.38)$ & $0.64(0.35,1.15)$ & $21 / 659$ vs $1 / 50$ & $0.47(0.13,1.68)$ & $0.42(0.09,2.10)$ \\
\hline \multicolumn{7}{|l|}{ Malignancies* } \\
\hline Overall & $22 / 1099$ vs $27 / 3138$ & $2.32(0.84,6.44)$ & $1.89(0.93,3.84)$ & $22 / 1099$ vs $24 / 1103$ & $0.77(0.29,2.06)$ & $0.93(0.20,4.27)$ \\
\hline First-line & $3 / 171$ vs $14 / 1191$ & NR & NR & $3 / 171$ vs $17 / 304$ & $0.75(0.09,6.13)$ & $0.36(0.03,3.83)$ \\
\hline Second-line & $6 / 409$ vs $8 / 1132$ & $4.61(0.98,21.7)$ & $N R$ & $6 / 409$ vs $6 / 119$ & NR & NR \\
\hline Third- or greater line & $13 / 659$ vs $5 / 1192$ & $0.35(0.04,3.08)$ & $1.34(0.39,4.57)$ & $13 / 659$ vs $1 / 50$ & $0.61(0.06,5.75)$ & NR \\
\hline \multicolumn{7}{|c|}{ Non-melanoma skin cancers } \\
\hline Overall & $37 / 1099$ vs $25 / 3138$ & $1.26(0.69,2.29)$ & $1.10(0.57,2.11)$ & $37 / 1099$ vs $20 / 1103$ & $0.90(0.33,2.46)$ & $1.05(0.22,4.98)$ \\
\hline First-line & $1 / 171$ vs $13 / 1191$ & NR & NR & $1 / 171$ vs $15 / 304$ & $0.88(0.10,7.37)$ & $0.62(0.05,7.28)$ \\
\hline Second-line & $15 / 409$ vs $7 / 1132$ & $4.08(0.80,20.67)$ & NR & $15 / 409$ vs $4 / 119$ & NR & NR \\
\hline Third- or greater line & $21 / 659$ vs $5 / 1192$ & $0.35(0.0,3.08)$ & $1.34(0.39,4.57)$ & $21 / 659$ vs $1 / 50$ & $0.61(0.06,5.75)$ & NR \\
\hline
\end{tabular}

*Patients with prior history of malignancy were excluded

${ }^{+}$Using inverse probability of treatment weights with further adjustment for time-varying age and disease duration, HAQ-DI, pain and patient global scores, RDCI and GC treatment duration

CDMARD biologic synthetic disease-modifying antirheumatic drug, $\mathrm{Cl}$ confidence interval, csDMARD conventional synthetic disease-modifying antirheumatic drug, GC glucocorticoid, HAQ-DI Health Assessment Questionnaire-Disability Index, HR hazard ratio, NR not reported due to low event numbers causing inability to achieve convergence, $R A$ rheumatoid arthritis, $R C D /$ Rheumatic Disease Comorbidity Index

Table 3 Incidence rates for malignancy, infections and autoimmune disease outcomes by treatment

\begin{tabular}{|c|c|c|c|c|c|c|}
\hline \multirow[t]{2}{*}{ Outcomes } & \multicolumn{2}{|l|}{ Abatacept } & \multicolumn{2}{|c|}{ Other bDMARDs } & \multicolumn{2}{|l|}{ csDMARDs } \\
\hline & $\begin{array}{l}\text { No. of events/ } \\
\text { no. of patients }\end{array}$ & $\operatorname{IR}(95 \% \mathrm{Cl})^{*}$ & $\begin{array}{l}\text { No. of events/ } \\
\text { no. of patients }\end{array}$ & $\operatorname{IR}(95 \% \mathrm{Cl})^{*}$ & $\begin{array}{l}\text { No. of events/ } \\
\text { no. of patients }\end{array}$ & $\operatorname{IR}(95 \% \mathrm{Cl})^{*}$ \\
\hline$\overline{\text { Overall malignancy }}^{\dagger}$ & $22 / 1099$ & $0.76(0.47,1.15)$ & $27 / 2592$ & $0.50(0.33,0.72)$ & $24 / 1093$ & $0.86(0.55,1.27)$ \\
\hline Lung & $1 / 1099$ & $0.012(0.00,0.07)$ & $1 / 2592$ & $0.02(0.00,0.10)$ & 0/1093 & $0.00(0.00,0.13)$ \\
\hline NMSC & 20/1099 & $0.55(0.40,0.73)$ & $25 / 2592$ & $0.46(0.30,0.68)$ & 20/1093 & $0.71(0.43,1.10)$ \\
\hline Hospitalized infections & $37 / 1496$ & $1.63(1.15,2.24)$ & $135 / 3490$ & $1.78(1.49,2.11)$ & $77 / 1520$ & $1.90(1.50,2.38)$ \\
\hline Opportunistic & $2 / 1496$ & $0.09(0.01,0.31)$ & $6 / 3490$ & $0.08(0.03,0.17)$ & $3 / 1520$ & $0.07(0.02,0.21)$ \\
\hline Pneumonia & $13 / 1496$ & $0.57(0.30,0.97)$ & $80 / 3490$ & $1.04(0.82,1.29)$ & $50 / 1520$ & $1.03(0.79,1.33)$ \\
\hline Lupus & $1 / 1496$ & $0.04(0.00,0.24)$ & $0 / 3490$ & $0.00(0.00,0.05)$ & $3 / 1520$ & $0.07(0.02,0.21)$ \\
\hline Psoriasis & $15 / 1496$ & $0.66(0.37,1.09)$ & $30 / 3490$ & $0.39(0.26,0.55)$ & $15 / 1520$ & $0.36(0.20,0.59)$ \\
\hline Multiple sclerosis $^{\dagger}$ & $1 / 1484$ & $0.04(0.00,0.24)$ & $0 / 3471$ & $0.00(0.00,0.05)$ & 0/1515 & $0.00(0.00,0.09)$ \\
\hline All hospitalizations & $637 / 1496$ & $28.83(26.64,31.16)$ & $2001 / 3490$ & $28.26(27.03,29.53)$ & $1292 / 1520$ & $32.53(30.78,34.36)$ \\
\hline All deaths ${ }^{\ddagger}$ & $128 / 1496$ & $2.99(2.49,3.55)$ & $162 / 3490$ & $2.16(1.84,2.52)$ & $117 / 1520$ & $2.78(2.30,3.33)$ \\
\hline
\end{tabular}

There were no events for breast cancer, lymphoma or tuberculosis in any treatment group

*Per 100 patient-years

${ }^{\dagger}$ Patients with prior history of malignancy or multiple sclerosis were excluded

${ }^{\ddagger}$ Deaths from all causes within 1 year of last use of abatacept or of last study observation for control subjects

bDMARD biologic disease-modifying antirheumatic drug, $C l$ confidence interval, $C S D M A R D$ conventional synthetic disease-modifying antirheumatic drug, IR

incidence rate, NMSC non-melanoma skin cancer 
Table 4 Incidence rates of infusion/injection reactions by bDMARD treatment

\begin{tabular}{|c|c|c|c|c|c|c|c|c|}
\hline \multirow[t]{3}{*}{ Outcomes } & \multirow{2}{*}{\multicolumn{2}{|c|}{ Abatacept }} & \multicolumn{6}{|l|}{ Other bDMARDs } \\
\hline & & & \multicolumn{2}{|l|}{ Overall } & \multicolumn{2}{|l|}{ TNFi } & \multicolumn{2}{|c|}{ Non-TNFi bDMARDs } \\
\hline & $\begin{array}{l}\text { No. of events/ } \\
\text { no. of patients }\end{array}$ & IR $(95 \% \mathrm{Cl})^{*}$ & $\begin{array}{l}\text { No. of events/ } \\
\text { no. of patients }\end{array}$ & $\operatorname{IR}(95 \% \mathrm{Cl})^{*}$ & $\begin{array}{l}\text { No. of events/ } \\
\text { no. of patients }\end{array}$ & $\operatorname{IR}(95 \% \mathrm{Cl})^{*}$ & $\begin{array}{l}\text { No. of events/ } \\
\text { no. of patients }\end{array}$ & $\operatorname{IR~}(95 \% \mathrm{Cl})^{*}$ \\
\hline Any infusion reaction & $115 / 1330$ & $\begin{array}{l}5.36(4.42 \\
6.43)\end{array}$ & $196 / 1336$ & $\begin{array}{l}9.25(8.00 \\
10.64)\end{array}$ & $106 / 985$ & $\begin{array}{l}7.00(5.73 \\
8.47)\end{array}$ & $74 / 501$ & $\begin{array}{l}9.38(7.36 \\
11.77)\end{array}$ \\
\hline $\begin{array}{l}\text { Severe infusion } \\
\text { reactions }\end{array}$ & $27 / 1330$ & $\begin{array}{l}1.26(0.83 \\
1.83)\end{array}$ & $41 / 1336$ & $\begin{array}{l}1.94(1.39 \\
2.63)\end{array}$ & $24 / 985$ & $\begin{array}{l}1.59(1.02 \\
2.36)\end{array}$ & $12 / 501$ & $\begin{array}{l}1.52(0.79 \\
2.66)\end{array}$ \\
\hline Any injection reaction & $53 / 626$ & $\begin{array}{l}8.19(6.13 \\
10.71)\end{array}$ & $573 / 1690$ & $\begin{array}{l}23.43(21.55, \\
25.43)\end{array}$ & $550 / 1679$ & $\begin{array}{l}22.62(20.76, \\
24.59)\end{array}$ & $3 / 20$ & $\begin{array}{l}12.46(2.57, \\
36.41)\end{array}$ \\
\hline $\begin{array}{l}\text { Severe injection } \\
\text { reactions }\end{array}$ & $3 / 626$ & $\begin{array}{l}0.46(0.10 \\
1.35)\end{array}$ & $46 / 1690$ & $\begin{array}{l}1.88(1.38 \\
2.51)\end{array}$ & $40 / 1679$ & $\begin{array}{l}1.65(1.18 \\
2.24)\end{array}$ & $1 / 20$ & $\begin{array}{l}4.15(0.11 \\
23.14)\end{array}$ \\
\hline $\begin{array}{l}\text { Severe injection or } \\
\text { infusion reactions }\end{array}$ & $37 / 1496$ & $\begin{array}{l}1.57(1.11 \\
2.17)\end{array}$ & $95 / 2648$ & $\begin{array}{l}2.31(1.87 \\
2.82)\end{array}$ & $65 / 2361$ & $\begin{array}{l}1.85(1.42 \\
2.35)\end{array}$ & $14 / 512$ & $\begin{array}{l}1.75(0.95 \\
2.93)\end{array}$ \\
\hline
\end{tabular}

*Per 100 patient-years

bDMARD biologic disease-modifying antirheumatic drug, $C l$ confidence interval, IR incidence rate, TNFi tumour necrosis factor-a inhibitor

injection reactions were observed with abatacept versus TNFis and other bDMARDs, which is consistent with the ATTEST and AMPLE trials that showed infusion and injection reactions were more frequent with infliximab and adalimumab than with abatacept $[11,16]$. Furthermore, an examination of healthcare data indicated the IRs of hypersensitivity reactions were lower for abatacept than for other injectable bDMARDs [24].

Although early, aggressive treatment strategies and the use of bDMARDs have improved treatment outcomes in RA [1, 40], safety concerns have been raised [3]. Research on the comparative risks and benefits of treatment using observational data have become critical, as comparative safety data from RCTs are scarce. Conducting an appropriate analysis to address channelling bias in observational studies is challenging; however, the use of MSM methodology to adjust for time-varying confounders by weighting for the treatment groups where the baseline characteristics were balanced allowed us to obtain less biased estimates [32]. This methodology also addresses the attrition bias between treatment groups by weighting for the censoring distribution and balancing the characteristics of patients lost to follow-up with those who were followed up.

Despite using a strong methodology, our study had some limitations. First, the numbers of events, and accordingly incidence rates, reported were lower than in previous observational studies, which precluded the construction of models to assess the risk of different malignancies and hospitalized infections. It is possible that the inclusion of different study populations and the application of the strict validation process in FORWARD, although increasing the accuracy of the events reported, may be among the reasons for lower incidence rates of safety events than in previous observational studies. In addition, patients who are possibly in better health may be more likely to participate in FORWARD than those who are frail and at higher risk of infection and cancer.
This participation bias can also explain the low incidence rates of the events. Moreover, due to the self-reported nature of the data, some events may not have been recorded. Second, our sample size was inadequate to examine the safety risks associated with abatacept compared with individual bDMARDs or classes of bDMARDs. Furthermore, the analysis population included both biologic-naïve and biologic-experienced patients, for whom safety risks could differ. In order to address this, we added the number of previous bDMARDs to the model. We also performed a subgroup analysis on biologic-naïve and biologic-experienced patients (Table 2); however, the sample size was not adequate to see trends in safety risks. There is the potential for time-lag bias due to the 10-year follow-up period, particularly as patients were allowed to contribute to different treatment groups and drug indications may change over time. However, calendar matching will have minimized this potential bias [41]. The matching did not take into consideration that patients may switch treatments; however, continuing to include switchers in the study increased the number of patients included. Lastly, although our analyses included several clinical confounders including disease severity measures, unmeasured confounders could be present in this observational study.

\section{Conclusions}

Our study showed that abatacept treatment in patients with RA is associated with low IRs of malignancies, infections, autoimmune diseases and infusion/injection reactions. Our findings suggest the risks of hospitalized infections, malignancies and psoriasis are similar with abatacept and csDMARDs and that the safety profile for abatacept versus other bDMARDs is favourable in terms of hospitalized infections and infusion/injection reactions. Given that patients with RA are already at a higher risk of malignancy and infections than the general population, our findings are likely to be of clinical interest in 
making therapeutic decisions. However, additional observational research with longer follow-up periods is needed to fully evaluate the comparative safety of abatacept versus other DMARDs in terms of malignancy and mortality.

\section{Additional files}

Additional file 1: Table S1. ICD-9-CM codes for hospitalized infections. (DOCX $12 \mathrm{~kb}$ )

Additional file 2: Table S2. ICD-9-CM codes for malignancies. (DOCX $12 \mathrm{~kb}$ )

Additional file 3: Table S3. ICD-9-CM codes for autoimmune diseases. (DOCX $11 \mathrm{~kb})$

\section{Abbreviations}

AEs: Adverse events; bDMARDs: Biologic DMARDs; Cls: Confidence intervals; csDMARDs: Conventional synthetic DMARDs; DMARDs: Disease-modifying antirheumatic drugs; GC: Glucocorticoid; HAQ-DI: Health Assessment Questionnaire-Disability Index; HR: Hazard ratios; IPTWs: Inverse probability of treatment weights; IRs: Incidence rates; IV: Intravenous; MSMs: Marginal structural models; NMSCs: Non-melanoma skin cancers; RA: Rheumatoid arthritis; RCTs: Randomized controlled trials; Sls: Serious infections; TNFis: Tumour necrosis factor-a inhibitors

\section{Publisher's Note}

Springer Nature remains neutral with regard to jurisdictional claims in published maps and institutional affiliations.

\section{Acknowledgements}

We thank all of the patients who participated in FORWARD that made this important study possible. Professional medical writing and editorial assistance was provided by Linda Brown at Caudex and was funded by Bristol-Myers Squibb.

\section{Grant support}

Dr. Michaud was supported by grants from the Rheumatology Research Foundation Investigator Award and Pfizer.

\section{Authors' contributions}

$\mathrm{GO}, \mathrm{SP}, \mathrm{TAS}$ and $\mathrm{KM}$ contributed to the design of the analysis. SP, RS and $\mathrm{KM}$ contributed to the acquisition of data. GO, SP, RS, TAS and KM contributed to the analysis and interpretation of the data. All authors participated in the development of this manuscript, and read and approved the final version submitted for publication.

\section{Authors' information}

Teresa A Simon was affiliated to Bristol-Myers Squibb, Princeton, NJ, USA at the time of the study.

\section{Funding}

This study was sponsored by Bristol-Myers Squibb.

\section{Availability of data and materials}

Bristol-Myers Squibb policy on data sharing may be found at https://www. bms.com/researchers-and-partners/independent-research/data-sharingrequest-process.html.

\section{Ethics approval and consent to participate}

Not applicable.

\section{Consent for publication}

Not applicable.

\section{Competing interests}

TAS is an employee and shareholder of Bristol-Myers Squibb.

\section{Author details}

${ }^{1}$ University of Nebraska Medical Center, Omaha, NE, USA. ${ }^{2}$ FORWARD, The National Databank for Rheumatic Diseases, Wichita, KS, USA. ${ }^{3}$ Bristol-Myers Squibb, Princeton, NJ, USA.

Received: 30 November 2018 Accepted: 17 May 2019

Published online: 07 June 2019

\section{References}

1. Lacaille D, Avina-Zubieta JA, Sayre EC, Abrahamowicz M. Improvement in 5year mortality in incident rheumatoid arthritis compared with the general population-closing the mortality gap. Ann Rheum Dis. 2017;76(6):1057-63.

2. Nam JL, Takase-Minegishi K, Ramiro S, Chatzidionysiou K, Smolen JS, van de Heijde D, et al. Efficacy of biological disease-modifying antirheumatic drugs: a systematic literature review informing the 2016 update of the EULAR recommendations for the management of rheumatoid arthritis. Ann Rheum Dis. 2017;76(6):1113-36.

3. Ramiro S, Sepriano A, Chatzidionysiou K, Nam JL, Smolen JS, van der Heijde D, et al. Safety of synthetic and biological DMARDs: a systematic literature review informing the 2016 update of the EULAR recommendations for management of rheumatoid arthritis. Ann Rheum Dis. 2017;76(6):1101-36.

4. Smitten AL, Choi HK, Hochberg MC, Suissa S, Simon TA, Testa MA, et al. The risk of hospitalized infection in patients with rheumatoid arthritis. J Rheumatol. 2008:35(3):387-93.

5. Simon TA, Thompson A, Gandhi KK, Hochberg MC, Suissa S. Incidence of malignancy in adult patients with rheumatoid arthritis: a meta-analysis. Arthritis Res Ther. 2015;17:212.

6. Genovese MC, Becker JC, Schiff M, Luggen M, Sherrer Y, Kremer J, et al. Abatacept for rheumatoid arthritis refractory to tumor necrosis factor alpha inhibition. N Engl J Med. 2005;353(11):1114-23.

7. Genovese MC, Schiff M, Luggen M, Becker JC, Aranda R, Teng J, et al. Efficacy and safety of the selective co-stimulation modulator abatacept following 2 years of treatment in patients with rheumatoid arthritis and an inadequate response to anti-tumour necrosis factor therapy. Ann Rheum Dis. 2008:67(4):547-54

8. Kremer JM, Dougados M, Emery P, Durez P, Sibilia J, Shergy W, et al. Treatment of rheumatoid arthritis with the selective costimulation modulator abatacept: twelve-month results of a phase $\mathrm{llb}$, double-blind, randomized, placebo-controlled trial. Arthritis Rheum. 2005:52(8):2263-71.

9. Kremer JM, Genant HK, Moreland LW, Russell AS, Emery P, Abud-Mendoza C, et al. Effects of abatacept in patients with methotrexate-resistant active rheumatoid arthritis: a randomized trial. Ann Intern Med. 2006;144(12):865-76.

10. Kremer JM, Westhovens R, Leon M, Di Giorgio E, Alten R, Steinfeld S, et al. Treatment of rheumatoid arthritis by selective inhibition of T-cell activation with fusion protein CTLA4lg. N Engl J Med. 2003;349(20):1907-15.

11. Schiff M, Keiserman M, Codding C, Songcharoen S, Berman A, Nayiager S, et al. Efficacy and safety of abatacept or infliximab vs placebo in ATTEST: a phase III, multi-centre, randomised, double-blind, placebo-controlled study in patients with rheumatoid arthritis and an inadequate response to methotrexate. Ann Rheum Dis. 2008:67(8):1096-103.

12. Schiff M, Pritchard C, Huffstutter JE, Rodriguez-Valverde V, Durez P, Zhou X, et al. The 6-month safety and efficacy of abatacept in patients with rheumatoid arthritis who underwent a washout after anti-tumour necrosis factor therapy or were directly switched to abatacept: the ARRIVE trial. Ann Rheum Dis. 2009:68(11):1708-14.

13. Weinblatt ME, Schiff M, Valente R, van der Heijde D, Citera G, Zhao C, et al. Head-to-head comparison of subcutaneous abatacept versus adalimumab for rheumatoid arthritis: findings of a phase IIIb, multinational, prospective, randomized study. Arthritis Rheum. 2013:65(1):28-38.

14. Moreland LW, Alten R, Van den Bosch F, Appelboom T, Leon M, Emery P, et al. Costimulatory blockade in patients with rheumatoid arthritis: a pilot, dose-finding, double-blind, placebo-controlled clinical trial evaluating CTLA$4 \mathrm{lg}$ and LEA29Y eighty-five days after the first infusion. Arthritis Rheum. 2002:46(6):1470-9.

15. Weinblatt M, Combe B, Covucci A, Aranda R, Becker JC, Keystone E. Safety of the selective costimulation modulator abatacept in rheumatoid arthritis patients receiving background biologic and nonbiologic disease-modifying antirheumatic drugs: a one-year randomized, placebo-controlled study. Arthritis Rheum. 2006;54(9):2807-16.

16. Weinblatt ME, Moreland LW, Westhovens R, Cohen RB, Kelly SM, Khan N, et al. Safety of abatacept administered intravenously in treatment of 
rheumatoid arthritis: integrated analyses of up to 8 years of treatment from the abatacept clinical trial program. J Rheumatol. 2013;40(6):787-97.

17. Alten R, Kaine J, Keystone E, Nash P, Delaet I, Genovese MC. Long-term safety of subcutaneous abatacept in rheumatoid arthritis: integrated analysis of clinical trial data representing more than four years of treatment. Arthritis Rheumatol. 2014:66(8):1987-97.

18. Cabral VP, Andrade CA, Passos SR, Martins MF, Hokerberg YH. Severe infection in patients with rheumatoid arthritis taking anakinra, rituximab, or abatacept: a systematic review of observational studies. Rev Bras Reumatol Engl Ed. 2016;56(6):543-50.

19. Curtis JR, Xie F, Chen L, Baddley JW, Beukelman T, Saag KG, et al. The comparative risk of serious infections among rheumatoid arthritis patients starting or switching biological agents. Ann Rheum Dis. 2011;70(8):1401-6.

20. Curtis JR, Yang S, Patkar NM, Chen L, Singh JA, Cannon GW, et al. Risk of hospitalized bacterial infections associated with biologic treatment among U.S. veterans with rheumatoid arthritis. Arthritis Care Res (Hoboken). 2014; 66(7):990-7.

21. lannone F, Ferraccioli G, Sinigaglia L, Favalli EG, Sarzi-Puttini P, Atzeni F, et al. Realworld experience of tocilizumab in rheumatoid arthritis: sub-analysis of data from the Italian biologics' register GISEA. Clin Rheumatol. 2018;37(2):315-21.

22. Johnston SS, Turpcu A, Shi N, Fowler R, Chu BC, Alexander K. Risk of infections in rheumatoid arthritis patients switching from anti-TNF agents to rituximab, abatacept, or another anti-TNF agent, a retrospective administrative claims analysis. Semin Arthritis Rheum. 2013;43(1):39-47.

23. Wadstrom H, Frisell T, Askling J. Anti-rheumatic therapy in Sweden study group. Malignant neoplasms in patients with rheumatoid arthritis treated with tumor necrosis factor inhibitors, tocilizumab, abatacept, or rituximab in clinical practice: a nationwide cohort study from Sweden. JAMA Intern Med. 2017;177(11):1605-12.

24. Yun H, Xie F, Beyl RN, Chen L, Lewis JD, Saag KG, et al. Risk of hypersensitivity to biologic agents among Medicare patients with rheumatoid arthritis. Arthritis Care Res (Hoboken). 2017;69(10):1526-34.

25. Yun H, Xie F, Delzell E, Levitan EB, Chen L, Lewis JD, et al. Comparative risk of hospitalized infection associated with biologic agents in rheumatoid arthritis patients enrolled in medicare. Arthritis Rheumatol. 2016;68(1):56-66.

26. Harigai M, Ishiguro N, Inokuma S, Mimori T, Ryu J, Takei S, et al. Postmarketing surveillance of the safety and effectiveness of abatacept in Japanese patients with rheumatoid arthritis. Mod Rheumatol. 2016;26(4):491-8.

27. Nüßlein H, Alten R, Galeazzi M, Lorenz HM, Boumpas D, Nurmohamed MT, et al. Real-world effectiveness of abatacept for rheumatoid arthritis treatment in European and Canadian populations: a 6-month interim analysis of the 2-year, observational, prospective ACTION study. BMC Musculoskelet Disord. 2014;15(1):14

28. Solomon DH, Kremer JM, Fisher M, Curtis JR, Furer V, Harrold LR, et al. Comparative cancer risk associated with methotrexate, other non-biologic and biologic disease-modifying anti-rheumatic drugs. Semin Arthritis Rheum. 2014:43(4):489-97.

29. Wolfe F, Michaud K. The National Data Bank for rheumatic diseases: a multiregistry rheumatic disease data bank. Rheumatology (Oxford). 2011;50(1):16-24.

30. Michaud K. The National Data Bank for rheumatic diseases (NDB). Clin Exp Rheumatol. 2016;34(5 Suppl 101):S100-S1.

31. Robins JM, Hernan MA, Brumback B. Marginal structural models and causal inference in epidemiology. Epidemiology. 2000;11(5):550-60.

32. Fewell Z, Hernan MA, Wolfe F, Tilling K, Choi HK, Sterne AC. Controlling for time-dependent confounding using marginal structural models. Stata J. 2004; $4(4): 402-20$

33. D'Agostino RB, Lee ML, Belanger AJ, Cupples LA, Anderson K, Kannel WB. Relation of pooled logistic regression to time dependent Cox regression analysis: the Framingham Heart Study. Stat Med. 1990;9(12):1501-15.

34. Mori S, Yoshitama T, Hidaka T, Sakai F, Hasegawa M, Hashiba Y, et al. Comparative risk of hospitalized infection between biological agents in rheumatoid arthritis patients: a multicenter retrospective cohort study in Japan. PLoS One. 2017;12(6):e0179179.

35. Simon TA, Askling J, Lacaille D, Franklin J, Wolfe F, Covucci A, et al. Infections requiring hospitalization in the abatacept clinical development program: an epidemiological assessment. Arthritis Res Ther. 2010;12(2):R67.

36. Cooper GS, Bynum ML, Somers EC. Recent insights in the epidemiology of autoimmune diseases: improved prevalence estimates and understanding of clustering of diseases. J Autoimmun. 2009;33(3-4):197-207.
37. Somers EC, Thomas SL, Smeeth L, Hall AJ. Are individuals with an autoimmune disease at higher risk of a second autoimmune disorder? Am J Epidemiol. 2009;169(6):749-55.

38. Simon TA, Kawabata H, Ray N, Baheti A, Suissa S, Esdaile JM. Prevalence of co-existing autoimmune disease in rheumatoid arthritis: a cross-sectional study. Adv Ther. 2017;34(11):2481-90.

39. Genovese MC, Covarrubias A, Leon G, Mysler E, Keiserman M, Valente R, et al. Subcutaneous abatacept versus intravenous abatacept: a phase IIIb noninferiority study in patients with an inadequate response to methotrexate. Arthritis Rheumatol. 2011;63(10):2854-64.

40. Gwinnutt JM, Symmons DPM, MacGregor AJ, Chipping JR, Marshall T, Lunt $M$, et al. Twenty-year outcome and association between early treatment and mortality and disability in an inception cohort of patients with rheumatoid arthritis: results from the Norfolk Arthritis Register. Arthritis Rheumatol. 2017:69(8):1566-75.

41. Iudici M, Porcher R, Riveros C, Ravaud P. Time-dependent biases in observational studies of comparative effectiveness research in rheumatology. A methodological review. Ann Rheum Dis. 2019;78(4):562-9.

\section{Ready to submit your research? Choose BMC and benefit from:}

- fast, convenient online submission

- thorough peer review by experienced researchers in your field

- rapid publication on acceptance

- support for research data, including large and complex data types

- gold Open Access which fosters wider collaboration and increased citations

- maximum visibility for your research: over $100 \mathrm{M}$ website views per year

At BMC, research is always in progress.

Learn more biomedcentral.com/submissions 